\title{
Frequency, risk factors and materno-foetal outcomes among cases of Placenta previa at a tertiary care hospital: a two year study
}

\author{
Pamulaparthi Bindu Reddy, Gurram Swetha Reddy*
}

Department of Obstetrics and Gynecology, Narayana Medical College, Chinthareddypalem, Nellore, Andhra Pradesh, India

Received: 04 May 2019

Accepted: 16 May 2019

*Correspondence:

Dr. Gurram Swetha Reddy,

E-mail: sujatha2481@gmail.com

Copyright: (c) the author(s), publisher and licensee Medip Academy. This is an open-access article distributed under the terms of the Creative Commons Attribution Non-Commercial License, which permits unrestricted non-commercial use, distribution, and reproduction in any medium, provided the original work is properly cited.

\section{ABSTRACT}

Background: Placenta previa refers to the presence of placental tissue that extends over the internal cervical os. Placenta previa is linked to maternal hypovolemia, anaemia, and long hospital stay and with prematurity, low birth weight, low APGAR score in newborn. So it is very important to identify the condition at an early date to warn the condition thereby reducing the maternal and foetal morbidity and mortality. The present study was aimed to estimate the prevalence of PP, its associated predisposing risk factors and maternal morbidity, mortality and the perinatal outcome.

Methods: A prospective observational study for two years was conducted at a tertiary care hospital. Pregnant mothers with $>28$ weeks of age with $\mathrm{H} / \mathrm{o}$ ante partum haemorrhage were screened for placenta previa, confirmed by ultra sonography and included in the study. Clinical history, obstetric examination was done and followed up till the delivery. Maternal and foetal outcomes were recorded. Data analyzed by using SPSS version 20.

Results: $1.4 \%$ incidence of PP was noted, mean age of group was 29.17 \pm 1.6 years. Age group of 21-30 years, multiparity Gravida 2-4, previous history of caesarean section and less number of ante natal checkups were significant risk factors and LSCS was most common outcome. Prematurity, low birth weight and APGAR $<7$ score for 1 minute was common foetal outcomes.

Conclusions: Our study strongly suggests foetal surveillance programmes in cases of placenta previa. Measures should be made to bring awareness about PP, in urban slums and to increase medical checkups regularly. Making USG mandatory during every ANC and referral of cases of PP to tertiary care centres would definitely reduce the chances of morbidity and mortality.

Keywords: Ante partum haemorrhage, Low birth weight, Multiparity, Prematurity, Placenta previa

\section{INTRODUCTION}

Ante partum haemorrhage (APH) still remains one of the most serious threat during pregnancy. Vaginal bleeding during any trimester of pregnancy is an alarming condition to both the patients and the doctors. Bleeding during third trimester or after 20 weeks if gestation, placenta previa remains one of the cause and other placental causes may be abruption placenta or marginal separation of placenta. ${ }^{1}$ Placenta previa refers to the presence of placental tissue that extends over the internal cervical os. Sequelae include the potential for severe bleeding and preterm birth, as well as the need for caesarean delivery. In systematic reviews, the pooled prevalence of placenta previa is about 4 per 1000 births but varies widely from place to place and is dependable on medical facilities to diagnose the condition. This condition is due important as it is associated with significant maternal and foetal morbidity and mortality. ${ }^{2}$ Placenta previa has been linked to maternal hypovolemia, 
anaemia, and long hospital stay Placenta previa is associated with prematurity. However there is an observed debate that placenta previa is associated with low birth weight and low Apgar score. Hence diagnosis of this condition requires high resourced medical care facilities to reduce morbidity and mortality. The precise etiology of placenta previa is unknown; many risk factors such as increased maternal age, twin pregnancies, repeated caesarean section, previous uterine scar, grand parity, and malpresentations are a few mentioned risk factors. Importantly, the prevalence of placenta previa has been rising in parallel with the increasing rate of caesarean delivery and varies throughout the world and it has become a serious public health problem worldwide. ${ }^{3}$ The risk of developing PP increases significantly with increase in number of caesarean sections, with $\geq 3$ caesarean deliveries the chance of developing PP is $37 \%$. In developed countries with increased medical infrastructure and diagnostic facilities, PP is diagnosed even early without internal examination and availability of blood transfusion facilities have reduced the maternal mortality to zero level and with good foetal outcome. However in developing countries because of wide gap in extension of medical facilities and difference in patients profile between rural and urban the mortality ranges around from 1 to $5 \%$. So it is very important to identify the condition at an early date to warn the condition thereby reducing the maternal and foetal morbidity and mortality. ${ }^{4}$

The present study was aimed to study the prevalence of $\mathrm{PP}$, its associated predisposing risk factors and maternal morbidity and mortality. Our study also analyzed the perinatal outcome.

\section{METHODS}

The present prospective observational study was carried out in Department of Obstetrics and Gynaecology of a tertiary care hospital for a period of two years from January 2017 to December 2018. The study was presented before the institutional ethical committee and was approved. The study was carried out as per the guidelines of the committee. The study protocol was clearly explained to all the subjects and a written informed consent was obtained from them. All the cases attending the general OPD of the obstetrics were screened and suspected cases of placenta previa were confirmed by transabdominal ultra sonography and further by transvaginal ultrasound scan and included in the study. Gestational age of the cases in the study was determined by the last menstrual periods and first trimester ultrasound and cases with $>28$ weeks of age were included and cases with $<28$ weeks were excluded from the study. The socio demographic data with regard to age, menstrual history, and age at menarche, previous history of abortions, parity and previous history of caesarean section were noted by interviewing in a separate predesigned questionnaire sheet. The cases were thoroughly examined clinically and all the clinical findings, clinical history regarding duration of pain, bleeding, appreciation of foetal movements etc were noted and nutritional status, palor, edema, any signs of shock were noted.

Detailed obstetric examination included uterine tenderness, height of uterus in weeks, contractions, lie, presentation of foetus, mobility and engagement of foetus and Foetal heart sounds were noted. Regular records of vital parameters were noted. Classification of placenta and type was noted. Minor degrees of placenta previa cases were ensured for vaginal delivery unless developed complications and major degree of placenta previa cases underwent emergency caesarean section. The maternal and foetal outcomes were recorded for each case and the mothers and babies were assessed at the time of discharge. Babies requiring special attention were kept in NICU and monitored until discharge.

\section{Statistical analysis}

The statistical package for the social sciences (SPSS Version 20 for Windows) was used for data recording and statistical analysis. The descriptive analysis used included the mean, range, standard deviation, and frequency distribution.

\section{RESULTS}

In the present prospective observational study for a period of two years, 18547 pregnant women visited the obstetrics department for antenatal checkups. Among these cases, 264 cases were diagnosed as placenta previa (PP) with an incidence of $1.4 \%$ in our study. All these cases were followed till the end of delivery and the outcome of each case was noted along with the newborn. All the cases ended successfully with delivery, total of 18547 deliveries, singleton deliveries were 18480 $(99.64 \%)$ and twin deliveries were 67 (0.46\%). All the cases of PP had singleton deliveries.

Table 1: Demographic profile of cases in study.

\begin{tabular}{|lll|}
\hline Age in years & No & $\%$ \\
\hline$<20$ & 18 & 6.82 \\
\hline $21-25$ years & 64 & 24.24 \\
\hline $26-30$ years & 112 & 42.42 \\
\hline $31-35$ & 35 & 13.26 \\
\hline $36-40$ & 24 & 9.09 \\
\hline$>40$ & 11 & 4.17 \\
\hline Total & $\mathbf{2 6 4}$ & $\mathbf{1 0 0}$ \\
\hline Urban & 140 & 53.03 \\
\hline Rural & 124 & 46.97 \\
\hline
\end{tabular}

\section{Characteristics of study participants}

Table 1 summarizes the characteristics of study participants. Majority of the cases of PP in our study were in the age group of $26-30$ years $(42.42 \%)$ followed 
in order by $21-25$ years $(24.24 \%)$ and least was in age group of $>40$ years $(4.17 \%)$. The mean age of the study group was $29.17 \pm 1.6$ years; range was $18-42$ years. Majority of them were from urban area $53.03 \%$ and $46.97 \%$ from rural areas. However there was no statistical significance associated with area of locality in our study. Cases residing in urban areas had less chance of visiting an antenatal clinic regularly when compared with cases residing in rural localities.

\section{Association of risk factors}

Table 2 highlights the risk factors associated with the cases in the study. Age group of 21-30 years, multiparity Gravida 2-4, previous history of caesarean section and less number of ante natal checkups are found to be significantly associated with increased risk of placenta previa in our study. However increasing age and previous myomectomies had no association with PP. Malpresentations were associated with only $18.94 \%$ cases of PP in our study.

Table 2: Risk factors of cases in the study.

\begin{tabular}{|lll|}
\hline Maternal age & no & $\%$ \\
\hline$<20$ years & 18 & 6.82 \\
\hline $21-30$ years & 176 & 66.66 \\
\hline $31-40$ years & 59 & 22.35 \\
\hline$>40$ years & 11 & 4.17 \\
\hline Parity & & \\
\hline Primi & 54 & 20.45 \\
\hline Multi (2-3) & 200 & 75.76 \\
\hline Grand Multi (>4) & 10 & 3.79 \\
\hline Gravidity & & \\
\hline 1 & 75 & 28.41 \\
\hline $2-4$ & 154 & 58.33 \\
\hline$\geq 5$ & 34 & 12.88 \\
\hline Previous C/S & & \\
\hline Yes & 168 & 63.64 \\
\hline No & 96 & 36.36 \\
\hline No of ANC(Antenatal Checkups) & \\
\hline$<4$ & 114 & 43.18 \\
\hline$>4$ & 150 & 56.82 \\
\hline Malpresentations & & \\
\hline Yes & 50 & 18.94 \\
\hline No & 214 & 81.06 \\
\hline
\end{tabular}

\section{Maternal outcomes}

Table 3 highlights the different maternal outcomes in our study. Majority of the cases of PP in our study had more chances of LSCS (74.24\%) when compared with $25.76 \%$ who had normal vaginal delivery. $62.88 \%$ had no ante partum haemorrhage and in $37.12 \%$ of cases APH was observed mostly in $2^{\text {nd }}$ trimester. $27.27 \%$ of cases had post partum haemorrhage in our study. Blood transfusion was done in $35.61 \%$ of cases in the study. $80.30 \%$ had $<4$ days of hospital stay in our study. No case of maternal mortality was recorded in our study due to any cause. 11 cases of major placenta previa had haemostatic sutures Cho's and 9 cases of major placenta previa had vertical haemostatic sutures B-lynch. Febrile morbidity was noticed in 4 cases and sepsis in 17 cases in our study. However no cases of mortality were recorded.

Table 3: Maternal outcomes.

\begin{tabular}{|lll|}
\hline Type of delivery & No & $\%$ \\
\hline Vaginal & 68 & 25.76 \\
\hline LSCS & 196 & 74.24 \\
\hline Ante-partum haemorrhage & & \\
\hline Yes & 98 & 37.12 \\
\hline No & 166 & 62.88 \\
\hline post partum haemorrhage & & \\
\hline Yes & 72 & 27.27 \\
\hline No & 192 & 72.73 \\
\hline Blood transfusion & & \\
\hline Yes & 94 & 35.61 \\
\hline No & 170 & 64.39 \\
\hline Hospital stay & & \\
\hline$<4$ days & 212 & 80.30 \\
\hline$>4$ days & 52 & 19.70 \\
\hline
\end{tabular}

Table 4: Neonatal outcome of cases in the study.

\begin{tabular}{|lll|}
\hline Maturity In weeks & No & $\%$ \\
\hline$<30$ weeks & 21 & 7.95 \\
\hline $30-37$ weeks & 48 & 18.18 \\
\hline$>37$ weeks & 195 & 73.86 \\
\hline Preterm & 69 & 26.14 \\
\hline Birth weight (in kgs) & & \\
\hline$<1.5$ & 38 & 14.39 \\
\hline $1.5-3.0$ & 84 & 31.82 \\
\hline$>3.0$ & 140 & 53.03 \\
\hline Still born & 2 & 0.76 \\
\hline APGAR score (at 5 minutes) & & \\
\hline$>7$ & 162 & 61.36 \\
\hline$<7$ & 100 & 37.88 \\
\hline Respiratory distress syndrome & 21 & 7.95 \\
\hline
\end{tabular}

\section{Foetal outcomes associated with placenta previa}

Table 4 shows the relationship between foetal associations and their outcomes with placenta previa. Majority $73.86 \%$ were $>37$ weeks old and $26.14 \%$ were preterm and required monitoring. Only $14 \%$ of these cases required NICU admission based on maturity. $0.76 \%$ were still born and majority $53.03 \%$ were $>3 \mathrm{kgs}$ and $46.21 \%$ were $<3 \mathrm{kgs}$ by birth weight (Low Birth weight). $61.36 \%$ of cases recorded Apgar score of $>7$ at 1 minute and $37.88 \%$ with $<7$ at one minute. $22 \%$ of cases with Apgar score $<7$ at one minute required NICU admission. No cases of congenital anomalies were recorded in our study. 


\section{DISCUSSION}

The present study was conducted at a tertiary care hospital with all the medical and surgical facilities available for any emergency conditions. The incidence of cases presenting with Ante partum haemorrhage during the study period of two years was $34.22 \%(6347 / 18547)$. The incidence of placenta previa cases of all the pregnant cases attending the OPD was $1.4 \%$. Placenta previa as the cause of ante partum haemorrhage contributed in our study was $4.16 \%$ (264/6347). Findings of our study were similar to the findings of Kollmann $\mathrm{M}$ et al who reported the incidence of PP in his study as $1.8 \% .^{5}$ However certain studies from low income studies reported a higher incidence of PP from their studies ranging from $1.8 \%$ $6 \%$ which can be explained by increased number of caesarean sections, surgical procedures, maternal age and parity. The main difference could be difference in the study group and sample size. Majority of the deliveries were singleton $(99.64 \%)$ and the incidence of twin deliveries were $0.46 \%$. Our study observed very less incidence of twin deliveries when compared with the findings in the study of Choi $\mathrm{SH}$ et al who reported in his study to a maximum of $6 \% .^{6}$ This can be explained by the fact that increased practice of artificial inseminations among cases of infertility was the reason for increased incidence of twin deliveries. In our study, majority of the cases of PP were in the age group of 26-30 years $(42.42 \%)$ which is similar to the findings of Sarojini et al with an incidence of $48 \% .^{7}$ Majority of the cases in our study reported from urban areas where the medical care facilities are minimal and the ante natal checkups or visits were less in number. There was no statistical significance between locality and the placenta previa in our study.

In the present study, placenta previa was associated with increased risk of APH, PPH, Blood transfusions, prolonged hospital stay and increased chances of caesarean section in mothers and prematurity, low birth weight, NICU admission among newborn. In our study, incidence of placenta previa is observed more in cases of multiparous women (2-3) which is on par with the findings of Ananth $\mathrm{CV}$ et al. ${ }^{8}$ However findings of few studies mentioned higher incidence of PP in primipara than multipara which can be explained by the fact of hidden miscarriages and abortions and surgical procedures underwent before marriage. Gravida (2-4) was also significantly associated with increased risk in our study as on par with the findings in the reports of Razia Mehboob et al. ${ }^{9}$ The increased risk of placenta previa among multigravida women may be explained by degenerative change to the uterine vasculature, leading to under perfusion of the placenta, compensatory enlargement, and increased likelihood of implantation on the lower segment. In the present study, past history of caesarean section was found to have a fivefold increase chances of PP which is also similarly reported in the findings of studies of Anzaku AS and Musa J. ${ }^{10}$ This is explained by the fact that placenta implants on the previous caesarean scar or may be so deep to prevent placental separation or penetrate the uterine wall into surrounding structures. Our study also found that significantly less number of antenatal checkups was associated with more chances of PP and more maternal and foetal complications. However many studies differ in this as the better medical care facilities significantly reduce the complications associated with PP.

Majority of cases of PP (74.24\%) in our study had delivery by LSCS which is similar to the reports of Bhatt $\mathrm{AD}$ et al who found a nine fold risk of LSCS in cases of PP. ${ }^{11}$ Antepartum haemorrhage was significantly associated with PP and in our study it was observed mostly during the $2^{\text {nd }}$ trimester. These findings were in par with the reports of Faiz AS who reported a tenfold increased risk association with APH and it was observed mostly during the $3^{\text {rd }}$ trimester which differs from our study. ${ }^{12}$ Blood transfusion was done in $35.61 \%$ of cases in the study and had a threefold higher chances of blood transfusion than in cases with normal delivery. Findings of our study were consistent with findings of many studies as mentioned earlier and PP provoke severe haemorrhage during and after delivery because the lower segment does not constrict well the maternal blood supply which necessitates blood transfusion. The same condition also causes increased chances of PPH and prolongs the duration of hospital stay with also increased chances of performing LSCS. Hence it is important that blood transfusions and the obstetric emergency care be readily available at any facility treating women with placenta previa. No cases of maternal mortality were recorded at our hospital in our study as increased medical and surgical care facilities are emergency care was available to manage the condition effectively. Few studies reported a minimum of $2.5 \%$ to $7 \%$ of maternal mortality in their reports which can be due to the age group involved associated development of post operative complications associated with the condition.

Increased chances of low birth weight, prematurity and low Apgar score less than 7 at one minute was significantly associated foetal complications in our study. Findings of our studies were consistent with the findings of Ahmed SR and Kurude VN et al. ${ }^{13,14}$ The possible explanation for these could be that the bleeding associated with placenta previa may lead to hypoxia, intrauterine growth restriction, and prematurity with underdeveloped organ systems. Congenital malformations were not associated significantly with placenta previa in our study.

\section{CONCLUSION}

The incidence of placenta previa in our study was consistent with many past studies. Multigravida and previous caesarean section were associated maternal risk factors. Any association of these risk factors the mothers should be screened early for placenta previa. Placenta previa was also found to connote significant risk of 
severe, adverse maternal and foetal outcomes. Increased prematurity, more chance of NICU admissions are foetal outcomes associated with PP. So our study strongly suggests foetal surveillance programmes in cases of placenta previa. As the morbidity and mortality are preventable, measures should be made to bring awareness about PP, in urban slums and to increase medical checkups regularly. Making USG mandatory during every ANC and referral of cases of PP to tertiary care centres would definitely reduce the chances of morbidity and mortality.

Funding: No funding sources

Conflict of interest: None declared

Ethical approval: The study was approved by the Institutional Ethics Committee

\section{REFERENCES}

1. Leveno KJ, Alexander JM, Bloom SL. Placenta previa. In: Williams' Manual of Pregnancy Complications. 23rd ed. New York, NY: McGrawHill; 2013.

2. Sinha P, Kuruba N. Ante-partum haemorrhage: an update. J Obstet Gynaecol. 2008;28:377-81.

3. Downes KL. Previous prelabor or intrapartum cesarean delivery and risk of placenta previa. Am J Obstet Gynecol. 2015;212:669.e1-6.

4. Cresswell JA. Prevalence of placenta praevia by world region: a systematic review and meta-analysis. Trop Med Int Health. 2013;18:712-24.

5. Kollmann M, Gaulhofer J, lang U, Klaritsc P. Placenta previa: incidence, risk factors and outcome. J Matern Fetal Neonatal Med. 2016;29(9):1395-8.

6. Choi SH, Park YS, Shim KS, Choi YS, Chang JY, Hahn WH, et al. Recent trends in the incidence of multiple births and its consequences on perinatal problems in Korea. J Korean Med Sci. 2010;25(8):1191-6.

7. Sarojini, Malini KV, Radhika. Clinical study of placenta previa and its effect on maternal health and fetal outcome. Int J Reproduct Contracep Obstet Gynecol. 2016;5(10):3496-9.

8. Ananth CV, Wilox AJ, Cavitz DA, Bowes WA Jr, Luther ER. Effect of maternal age and parity on risk of uteroplacental bleeding in pregnancy. Intl J Obstet Gynecol. 2006;2:511-6.

9. Mehboob R, Ahmed N. Maternal and fetal outcome in placenta previa. Pakistan J Med Res. 2003;42(1).

10. Anzaku AS, Musa J. Placenta praevia: incidence, risk factors, maternal and fetal outcomes in a Nigerian teaching hospital. Jos J Med. 2009;6(1):42-6.

11. Bhatt AD, Meena A, Desai MR. Maternal and perinatal outcome in cases of placenta previa. Int $\mathbf{J}$ Sci Res. 2014;3(1):299-301.

12. Faiz AS, Ananth CV. Etiology and risk factors for placenta previa: an overview and meta-analysis of observational studies. J Matern Fetal Neonatal Med. 2003;13:175-90.

13. Ahmed SR, Aitallah A, Abdelghafar HM, Alsammani MA. Major placenta previa: rate, maternal and neonatal outcomes experience at a tertiary maternity hospital, sohag, Egypt: a prospective study. J Clin Diagno Res, 2015;9(11):QC17-9.

14. Kurude VN, Saha D. Study of maternal and perinatal outcome in placenta praevia at tertiary care center. Indian J Res. 2016;6(3):44-5.

Cite this article as: Reddy BP, Reddy GS.

Frequency, risk factors and materno-foetal outcomes among cases of Placenta previa at a tertiary care hospital: a two year study. Int J Reprod Contracept Obstet Gynecol 2019;8:2240-4. 